\title{
UNIVERSITYOF
}

FORWARD

THINKING

WESTMINSTER用

WestminsterResearch

http://www.westminster.ac.uk/westminsterresearch

\section{Substance misuse and parenting: Making drugs and gender in the Family Court}

Flacks, $\mathbf{S}$.

This journal article has been accepted for publication and will appear in a revised form, subsequent to peer review and/or editorial input by Cambridge University Press in the International Journal of Law in Context. This version is free to view and download for private research and study only. Not for re-distribution, re-sale or use in derivative works.

(C) Cambridge University Press, 2019

The final definitive version in the online edition of the journal article at Cambridge Journals Online is available at:

https://dx.doi.org/10.1017/S174455231900003X

The WestminsterResearch online digital archive at the University of Westminster aims to make the research output of the University available to a wider audience. Copyright and Moral Rights remain with the authors and/or copyright owners.

Whilst further distribution of specific materials from within this archive is forbidden, you may freely distribute the URL of WestminsterResearch: ((http://westminsterresearch.wmin.ac.uk/)).

In case of abuse or copyright appearing without permission e-mail repository@westminster.ac.uk 


\section{Substance misuse and parenting: Making drugs and gender in the Family Court}

\section{Introduction}

Evidence of the use or 'abuse'1 of psychoactive substances, particularly those designated illegal, has profound implications for parents who wish to retain care of, or contact with, their children in the UK. 'Substance misuse' is estimated to be involved in up to two-thirds of care applications (DoE, 2016) and, although it is "rarely the sole cause of family difficulties" and is "usually part of a complex web of co-existing problems" (NHS, 2012: 3), it has been associated with various health and development difficulties and is understood to be "a leading cause of child abuse and neglect" (Harwin et al. 2016: 5). Under the Children Act 1989, under-18s may be supervised by local authorities or removed from the care of their parents (through 'care' and 'supervision orders') if there is judged to be a significant risk of harm to the child or children. ${ }^{2}$ According to s.31(9), 'harm means ill-treatment or the impairment of health or development, including, for example, impairment suffered from seeing or hearing ill-treatment of another'. Harm has been found to encompass, for example, witnessing the domestic abuse of a parent, ${ }^{3}$ not attending school ${ }^{4}$ or not receiving adequate medical treatment, ${ }^{5}$ as well the use of substances. ${ }^{6}$ The European Court of Human Rights has held that taking children into care should generally be a last resort and temporary in order to preserve the rights of both parent and child to respect for family life. ${ }^{7}$ In private law cases, evidence of parental drug and/or alcohol use may preclude the use of mediation services following the breakdown of a relationship, ${ }^{8}$ and it is often used against one or both parents as reason to deny

\footnotetext{
${ }^{1}$ The lack of consensus about the meaning of terms such as 'addiction', 'dependence' and 'substance misuse' or 'abuse' is returned to below.

${ }^{2}$ S.31(2).

${ }^{3}$ Re R (Care: Rehabilitation in Context of Domestic Violence) [2006] EWCA Civ 1638

${ }^{4} \mathrm{Re} O$ (A Minor) (Care Order: Education: Procedure) 19922 FLR 7

${ }^{5} \mathrm{~F}$ v Solfolk [1981] 2 FLR 208

${ }^{6}$ As discussed at length in due course.

${ }^{7}$ K and T v. Finland (2001) 31 E.H.R.R. 18; Johanson v. Norway (1996) 23 E.H.R.R. 33; Reime v. Sweden (1992) 16 E.H.R.R. 155; Eriksson v. Sweden (1989) 12 E.H.R.R. 183

8 Practice Direction 12b, the 'Child Arrangements Programme' (para. 5.2).
} 
contact or residence (Peacey and Hunt, 2008; Hunt and MacLeod, 2008; Harding and Newnham, 2015).

Despite the importance of substance use to family law decisions, there has been only limited research into how harms are understood and constituted in court, and how this intersects with norms and expectations about parenting. Questions relating to parental substance 'misuse' (including alcohol) have remained almost entirely within the purview of researchers operating within the disciplines of social work and public health (see, for example, Kroll, 2004; Barnard and McKeganey, 2004; Holland et al., 2013; Comiskey, Milnes and Daly, 2017; Rhodes et al., 2010). In creating a conversation between the fields of family law and critical drug studies, the attempt in this paper is to attend much more closely to the ways in which substances are framed in family court judgements in order to provoke deeper reflection on the ways in which parental use is problematised. Using theoretical perspectives rooted in Science and Technology Studies (STS), feminist perspectives on female substance use, and drawing on a survey of approximately 150 reported cases, the aim is to remain attendant to the ontological multiplicity (Mol, 2002; Law, 2004) of objects that emerge from attempts to stabilise drug harms in legal narratives. Despite the variability of phenomena such as 'drugs' and 'addiction', they were presented in the cases as stable and definitive as judges sought to articulate the risks and harms associated with parental drug use. This process resulted in the emergence of a number of 'collateral realities' (Law, 2011), including that capable parenting is, for the most part, contingent on abstinence from substances, albeit mainly those that are illegally obtained, and that 'drugs' cause family breakdown and damage to children. Substance use by mothers was enacted as particularly problematic, and the framing of the relationship between drugs and domestic violence raised troubling implications for how responsibility for abuse is attributed. The discussion will begin with an exploration of the theoretical grounding for the paper, and an examination of the intersection between substances, parenting and family law, before embarking on an analysis of the judgements.

\section{'Drugs', gender and the family}

Although children have long been a focus for concerns about drugs (Courtwright, 2001; Flacks, 2017), parental substance use emerged as a specific and significant 
policy concern in the early 2000s following the release of a flurry of reports into the 'hidden harms' experienced by children. Authored by the Advisory Council on the Misuse of Drugs (ACMD), one of the first, and most influential, of these was Hidden Harm: Responding to the Needs of Children of Problem Drug Users, published in 2003. According to the report, "Parental problem drug use can and does cause serious harm to children at every age from conception to adulthood" (Home Office, 2003: 3). Reports were also produced by nongovernmental organisations (Joseph Rowntree Trust, 2004; Tunnard, 2002), and researchers warned that, given that two to three per cent of all children in the UK under the age of 16 were estimated to have parents with drug problems, "it is an issue to which we have woken up late" (Barnard and McKeganey, 2004: 552). A later publication by the Children's Commissioner for England highlighted the dearth of services for children affected by parental alcohol misuse (Adamson and Templeton, 2012), and some researchers subsequently argued that "Drug-addicted parents should be given 12-18 months to get drug-free or lose their children" (Children and Young People Now, 2009). The relatively recent surge in concern for parental substance use has dovetailed with an increasing policy focus on the responsibilisation of 'failing' parents (Lister, 2003) involving the use of coercive measures such as Parenting Orders to target those who fall short (Holt 2008), and the expectation that mothers, in particular, police themselves as incubators of future citizens (Gillies, 2005, 2007; Cain, 2011). Working class or socially excluded mothering practices have been subject to particular scrutiny in market-based societies and parents are increasingly seen as primarily responsible to the exclusion of structural variables such as poverty and class - for guaranteeing their future as economically-productive citizens (Gillies, 2014).

Addiction, although a contested and ambiguous term, has been called "one of liberalism's most despised, and most necessary, creatures" because it threatens (and reinforces) idealised expectations of the autonomous, individualised subject (Fraser and valentine, 2008: 172). Since the essence of addiction is usually located in bodily pathology, deficit, or vulnerability (Weinberg, 2002) "drug users are viewed as materially constituted subjects whose very embodied 'essence' is to be marked as deviant, abject, and 'other"' (Campbell and Ettorre, 2013: 2). If societies are defined by their opposition to addiction (Fraser, 2017: 130; Derrida, 1993; Keane, 2002), and drug use continues to attract moral disapprobation, it might be expected that 
evidence of consumption would challenge norms about responsible parenthood. Mothers and fathers who use substances are not, however, exposed to equal levels of surveillance, stigma and intervention. Although research on female substance use remains relatively sparse (Moore and Measham, 2013), women consumers tend to be portrayed as doubly deviant and more disturbed than their male counterparts because of their transgression of traditional gender roles (Ettorre, 2007; Cambell and Ettorre, 2011). Good mothers do not use substances, and those that do (particularly if pregnant) are portrayed as negligent and unfit. Couvrette et al. (2016: 292) explain how a 'good mother' is expected to be

thoughtful, altruistic, patient, devoted to her children, and fulfilled by her mothering role... She sets her own goals and interests aside, devotes herself entirely to her children, and does not make life choices that may impede her children's development.

According to Campbell and Ettorre (2013: 179) women's drug addiction has thus consistently been framed within the "domain of social reproduction" in a society in which "women are assumed to be the linchpins of social order, family life, and biosocial (and cultural) reproduction". In the US, social workers sought to regulate mothers suspecting of using substances, including cocaine and marijuana, as soon as they were criminalised in the early 1900s (Boyd and Carter, 2011). In the late 1950 s and early 1960s, maternal drug use was identified as a risk to the developing foetus and there was an emergence of 'new ideologies' about 'dangerous' drugusing mothers (Boyd and Carter, 2011: 5; Boyd, 1999; 2004). The 'crack scares' of the 1980s similarly identified mothers as a particular threat to the health, wellbeing and survival of their infants, and women faced criminal charges for giving birth to infants who failed drug tests (Roberts, 1991).

Women addicts are expected to enter treatment not necessarily for themselves but "in order to become stable enough to provide social stability for others - often for their male partners and children" (Campbell and Ettorre (2013: 179). Women may well try to conceal their drug and alcohol problems from health and social services, a choice that, for Campbell and Ettorre (2011: 180) should be viewed as a rational response to the social stigma faced by drug-using women, and might equally be understood as a reasonable reaction to the threat of child removal (Barnard and 
Barlow, 2003; Kroll and Taylor, 2003). Research with service providers has found that substance use by women may be framed as "essentially harmful" via a "gendered responsibilisation of women as foetal incubators and primary caregivers of infants" (Benoit et al., 2014: 260). It has been suggested that risk has supplanted deviance as the predominant governing discourse in advanced liberal societies (Moore and Valverde, 2000), and that this has been incorporated in to policy on parental substance use (Bancroft and Wilson, 2007: 320). Family legal scholars will be familiar with the framing of women's behaviour according to their reproductive role, and also to the ways in which questions relating to children's rights and welfare may serve as forces for normalisation, or 'codes' for other concerns (Van Krieken, 2005: 33; Berns, 2000; Reece, 1996).

\section{Approach}

In tackling questions relating to the constitution of 'drugs', addiction and parenting in the family court, the approach taken in this paper aligns with a body of research, rooted in Science and Technology Studies, and using theoretical perspectives developed by Jacque Dilleuze, Bruno Latour, John Laws and AnneMarie Mol, among others, that reflects on the ways in which problems such as addiction are 'made' within (rather than pre-exist) scientific, health and legal discourses. According to this perspective, addiction, the addict and other 'realities' such as 'drugs' and their harms, are unstable objects that are performed in court rather than simply 'identified' or diagnosed as pre-existing behaviours or objects. Such approaches are informed by the recognition that addiction is a concept that defies any clear and consistent definition (Fraser, Moore and Keane, 2014), and that the 'drugs' label is a regulatory category that has no material essence, nor any coherent or stable propensity to cause harm. This is not a purely relativist or rhetorical position, but rather follows a stream of critical scholarship that, instead of seeking to uncover the 'truth' about drugs, endeavours to understand the ways in which drug effects are discursively produced and what consequences may ensue (Fraser, Moore and Keane, 2014; Seear, 2015; Race, 2011; Hart and Moore, 2014). Terms such as 'addiction' and 'drugs' tend to be presented as fixed and coherent despite their lack of essence or material character (Law, 2011) and are 'made' within an ontological politics of knowledge production (Mol, 2002). For example, a critical approach to causality rooted in assemblage thinking posits that 
causes and effects are "ontologically inseparable from epistemological practices" (Hart and Moore, 2014: 398). As Hart and Moore go on to explain in the context of alcohol epidemiology:

To put in another way, where effects are "caused" by alcohol use, systems for the definition and measurement of effects are as much a pre-condition for these effects as alcohol itself. These systems of definition and measurement also enact a particular version of alcohol that, in each case, might be done differently (ibid.).

When considering causality in respect of drug effects and parenting, one might therefore expect a range of agential forces to be relevant in the assemblage of drug effects beyond the properties of the drug itself (Moore, 2014; Duff, 2012). This approach departs from more established social constructionist perspectives by acknowledging that the process of making and enacting particular concepts is not stable and finite, but open to development and re-constitution in different contexts. It is thus important to remain attendant the 'discursive dynamics' (Seear and Fraser, 2014) of objects, and to interrogate the 'illusion' of stability and coherence pervading discourses on drugs, particularly given the stigma and discrimination with which drug users tend to be confronted.

The court provides particularly fertile ground for the making of realities, since it is a place in which "ideas of truth and justice are co-constructed" (Jasanoff, 1995: xiv). Kate Seear (2017) has observed how legal systems position drug and alcohol 'problems' as central to legal deliberation. As a result, the law

assumes that addiction is the cause of human action and foundational to complex social phenomena such as criminal offending and family violence. This way of viewing human agency forecloses other ways of seeing the world, including the possibility that individual actions are shaped by factors other than alcohol and other drug consumption (see also Seear \& Fraser, 2016).

It is argued below that, in the supposedly neutral and objective evaluation of evidence, the family court determines how the best interests of the child might best be served, and in so doing shapes and fashions those 'realities' (bad parenting, drugs, addiction and so on) that it presumes to rectify. The purpose is not to argue that the judicial version of reality is incorrect, as this would suggest that a correct, 
pre-existing reality is 'out there' ready to be discovered. Rather, it is argued that by identifying the tensions between different versions of realities, there is an opportunity for destabilising existing assumptions, and offering new entry points for considering the relationship between substance use and parenting.

\section{Methods}

A total of 178 cases, identified using search terms relating to substance use ('drugs', 'substance misuse', 'addiction' and so on) and disputes about care and contact (including 'Children Act', 'contact', 'residence'), were downloaded from the UK Westlaw database. In 117 of these cases, substance use was explicitly mentioned as relevant to the outcome decision. Although a variety of search terms were used, the majority of the cases related to care orders $(n=79)$, sometimes in combination with decisions about parental contact $(n=16)$. A smaller proportion of cases solely concerned private disputes between parents $(n=22)$. It is unclear why relatively few cases involved contact and residence disputes between parents, rather than public authorities, given the frequency with which allegations of drug use are levelled by parents against each other (Peacey and Hunt, 2008). It may be that the majority of such cases tend to be resolved out of court. The searches were not restricted to a specific time period, and were conducted during the summer of 2017.

The cases were then examined and coded for mention of substance use. The analysis was informed by the following questions: Is substance use, illicit and otherwise, incompatible with 'good enough' parenting? What is a 'drug' for the purposes of judicial evaluations of parenting? How are 'misuse', 'abuse' and 'addiction' defined and linked to parental capacity? As discussed further below, the precise ways in which substance use posed a risk to children was nebulously extrapolated in the judgements, although the risks may have been explained in the guise of expert evidence provided to the court (and thus not necessarily incorporated into the judgement). Given that much of the work done to stabilise addiction and 'drug' harms happens behind the scenes, or in court (through expert witnesses, particularly welfare and medical professionals), rather than within judgements or by the judiciary, future research might attend to such broader assemblages of 
knowledge production. The cases are not necessarily representative since they were selected for inclusion within legal databases and journals on the basis that they had some legal value, or held particular interest for lawyers and researchers. They represent a small proportion of those heard, in private, within family law courts across the country. It should also be noted that, by relying on case transcripts, the analysis privileges the judge's interpretation of the facts and legal principles. It is nevertheless argued that the cases have considerable epistemological value because they help readers to attend to the 'messy realities' and ontological politics of producing knowledge about addiction, parenting and drug harms, particularly when levelled by the most powerful of legal 'truth-tellers' (Mol and Law, 2002).

\section{Determining the risk to children}

The ways in which drug use was constituted as risky in the judgements varied, particularly in respect of what levels of consumption could be deemed problematic. As indicated above, it has been established that the use or 'abuse' of drugs and alcohol does not itself authorise a child's removal from his or her family. In $\operatorname{Re} B,{ }^{9}$ Lady Hale expressed it as follows:

'We are all frail human beings, with our fair share of unattractive character traits, which sometimes manifest themselves in bad behaviours which may be copied by our children. But the State does not and cannot take away the children of all the people who commit crimes, who abuse alcohol or drugs, who suffer from physical or mental illnesses or disabilities, or who espouse anti-social political or religious beliefs (para. 143).

While emphasising that the abuse of alcohol or drugs does not automatically authorise the child's removal, it is nevertheless reinforced here as a 'bad behaviour' and an 'unattractive trait'. In Bath and North East Somerset Council v The mother and others, ${ }^{10}$ in which evidence of drug use was particularly critical to the decision to deny care to the mother, His Honour Judge Wildblood QC argued that:

The fact that a parent may take drugs or may engage in criminal activity does not mean that the children of that parent should be deprived of the right to be

\footnotetext{
9 [2013] UKSC 33

10 [2017] EWFC B10
} 
brought up by that parent. There has to be an holistic evaluation of each child's welfare and the ability of each parent and each relevant family member to care for each child" (para. 69)

Like criminality, the use rather than 'abuse' of drugs is thus framed as a behaviour that is problematic and, one might infer, enough to impact on a parent's right to care for a child, but not the rights of children to be parented. Other judges suggested that any drug use can be enough to revoke care. In $K$ and $H$ Children, for example, Lord Justice Thorpe, said:

I do make it very clear to the father, having sat for 11 years at first instance as a judge of the Family Division dealing with cases of this nature day-in and day-out, that parents who deal in drugs or dabble in drugs or take drugs have great difficulty retaining the care of their children. ${ }^{11}$

Evidence of drug use has been used as reason to preclude contact in private law cases, ${ }^{121314}$ although some judges have distinguished between different levels of use, suggesting that only 'excessive' consumption of drink or drugs is relevant, discussed further below. ${ }^{15}$ In the child abduction case of $\operatorname{Re} A,{ }^{16}$ drug taking was described as "catching the bacillus" (para. 92), formulating drug use as threatening and infectious (disease-like), and in re B (A Child) (Care Proceedings: Threshold Criteria) ${ }^{17}$ it was determined that a father's "drug abuse" would "come much higher that the learning difficulties of the parents, or the "personal character defects" of the mother (para. 209).

In several judgements, there was an attempt to be more precise about the risks posed. In Re: G (Care Order) ${ }^{18}$, the risk of "getting hold" of drug paraphernalia that had been left in the mother's bedroom was judged to indicate negligence on her part (para. 21). Judges suggested that children's knowledge of drug-taking by parents and other adults constituted harm in itself as a result of the potential

\footnotetext{
11 [2007] 1 F.L.R. 2043 para. 24

12 H (A Child) [2005] EWCA Civ 1404, para. 57

${ }^{13}$ D, Petitioner Sheriff Court (South Strathclyde, Dumfries and Galloway) (Dumfries), 2012 S.L.T. (Sh

Ct) 73 , para. 37

${ }^{14}$ London Borough of Bromley v SJ \& Others 2014 WL 7255403, para. 44

${ }^{15}$ Per Dame Elizabeth Butler-Sloss P in Re S (a child) [2004] EWCA Civ 18, para. 24.

16 [2006] EWHC 3397 (Fam)

17 [2013] UKSC 33

18 [2003] EWHC 1711 (Fam)
} 
transmission of deviancy. In Bath ${ }^{19}$, for example, HHJ Wildblood QC said that the father had neglected to consider the risks "that his lifestyle [including drug use] poses for [the child]", including:

the risks to $D$ of living in a household where there are Class A drugs nor did he mention the lack of responsibility that he would be showing to his child by involving himself in that lifestyle - normalising drug taking, associating with other drug takers and making his lifestyle appear acceptable to a young child (para 88).

Whether the parent had taken drugs at home, or in the presence of, or while caring for, a child, was also pertinent in GA v LA, M, F, BH. ${ }^{20}$ According to Mr Recorder William Tyler QC:

[The social worker's] concerns were [also] that there is a nebulous but nonetheless real range of other risks and dangers which attach to even occasional and social emersion in drug culture and third that a jaded, exhausted carer the morning after such a night out is scarcely likely to be appropriately attentive and engaging (para. 28).

It was thus not only behaviours described as addiction, problem use or dependence that posed risks to children because of the potential for neglect, but 'drug environments' and occasional or recreational drug-taking. Drugs were understood to lead, inevitably, to exhaustion and being 'jaded' (thus diminishing parental capacity) the following day. While not able to name the precise risks of 'drug cultures', asserting that they were "nonetheless real" stabilised the threats posed by drugs as true and definitive, and identified drug users as deviant. At the same time, this suggested that drug harms were not reducible to the pharmacological risks of the substances themselves, as further discussed below. Similarly, in the Matter of $F$ (Children), ${ }^{21}$ a decisive question for the child welfare officer was whether the father was "still involved in the drug culture" and if the child had "been exposed to any of that" (para. 10). The potential risks of an intoxicated parent were further raised in a number of cases, although the distinctions between 'mere' consumption, intoxication and regular or daily use were not clarified. Being under the influence of substances,

\footnotetext{
19 [2017] EWFC B10

20 [2017] EWFC 15

21 [2015] EWCA Civ 1315
} 
including alcohol, has variously been found to pose a 'real risk' of causing hurt to a child, ${ }^{22}$ or to result in the child "undoubtedly suffering significant harm". ${ }^{23}$ Evidence of "binge drinking" has also been held against a mother. ${ }^{24}$ In general, there was a lack of specificity or consistency regarding the risks and nature of both drugs and problematic use, although the judgements nevertheless largely asserted the agentic power of drugs to 'do' harm, as discussed further below.

\section{Producing 'drugs'}

Legal and policy discourses are generally considered to reify the pharmacological properties of substances and their agentic power to produce effects, such as corrupting the autonomy and rationality of 'addicts', independently of other variables (Keane, 2002; Fraser, Moore and Keane, 2014; Hart and Moore, 2014). The Drugs Act 1971 penalises drugs offences based on the 'class' of substance and the purported severity of effects and risks according to chemical composition, as if these are stable and coherent (Shiner, 2009), and this system of classification imbues drug policy and legal practice. In the cases surveyed, a range of drugs - both licit and illicit - were constituted as stable entities that all had potentially deleterious effects on the ability to parent. In Re FC (A Child: Care or Supervision Order), ${ }^{25}$ caffeine and energy drinks were determined to be 'drugs' and therefore 'addictive' substances in addition to cannabis, alcohol and legal highs. The doctor in the case testified that it would be "almost impossible" to accurately diagnose the father's mental health

'because of his current excessive consumption of caffeine. In fact, from the age of twelve years, but more importantly from the age of eighteen years, he has excessively abused [c]annabis, alcohol, energy drinks, legal highs and caffeine. Hence effectively throughout his life, he has never been completely free of any drugs and has also never had minimal use of drugs or alcohol either' (para 27).

The term 'drug' might here be understood as a floating signifier, potentially attached to any substance in order to signify excess or deviant usage, an assignation that will

\footnotetext{
22 Tameside Metropolitan Borough Council v KH, AC, ISH, 2016 WL 07048590, para 88

${ }^{23}$ London Borough of Wandsworth v W [2014] EWHC 3682 (Fam), para. 57

${ }^{24}$ Local Authority 1 ("LA1"), Local Authority 2 ("LA2") v AF (mother), BF (father), CF, DF, EF (children) (By their Guardian [2014] EWHC 2042 (Fam), para. 153

252016 WL 06820853
} 
also depend on the identity and social position of the consumer (Goffman, 1963). Although the social and economic background of the parents in these cases are unknown, researchers have pointed out that separating those whose drug use is seen as 'recreational' from those for whom it is deemed 'problematic' rests on distinctions that are heavily classed, raced and gendered (Valentine and Fraser, 2008). Fraser, Moore and Keane (2014) have further observed that 'addiction' has been deployed to encompass an ever-growing range of behaviours. Excessive use of prescribed benzodiazepines were found, in the judgements, to impede good parenting, ${ }^{26}$ although anabolic steroids, while considered to be drugs, were not judged to pose any risk to children. ${ }^{27}$ It was generally accepted that opioid substances prescribed to users of heroin as replacement therapies, and which have very similar chemical compositions, were also 'drugs', although their use was also not thought to pose risks. In Re: $A$ (A Child), ${ }^{28}$ for example, the mother was considered to have

demonstrated significant improvements in a number of important areas: she is now drug-free, other than the prescribed Subutex [Buprenorphine] which she has taken for some time and which she can safely take in the same way in the future; she has a stable lifestyle (para. 83).

However, in $\operatorname{Re} A$ (Children), ${ }^{29}$ the mere "presence" in the family home of the mother's uncle, who was taking methadone, also used to treat heroin withdrawal, was understood to indicate a possible threat to the child concerned, although it is not clear whether the risks emanated from the substance or the uncle's supposed addiction. In $R$ (Children), ${ }^{30}$ the father, described by the judge as "effectively addicted to the drug", accepted that "his abuse of cannabis made him an irresponsible father and an irresponsible partner to the mother of his children" (para. 13)[my emphasis]. ${ }^{31}$ The mother's 'misuse' of cannabis was also an issue in $\operatorname{Re} A$ (Children) $)^{32}$ (para. 28), although consumption of the substance, while looked upon

\footnotetext{
${ }^{26}$ D, Petitioner Sheriff Court of South Strathclyde, Dumfries and Galloway at Dumfries 2012 S.L.T. (Sh Ct) 73

27 OCC V FG (mother), HI (father), J and K (by their guardian SS) 2017 WL 02844343, para. 73

282014 WL 4249987

292016 WL 05864928, para. 18

30 [2005] EWCA Civ 516

31 See also Re P (A Child: Assessment of Kinship Carers) 2014 WL 2931274

322016 WL 05864928
} 
unfavourably, was not considered to be unconducive to good parenting in Swindon Borough Council v NA, AW, DWR, The Children ${ }^{33}$, where the judge stated that:

It is a serious concern that $F$ still takes cannabis which is a class B drug but there is no evidence before me that his use of this drug has had any ill effect on his ability to parent [the child] to date (para. 54).

Reflecting the lack of clarity or consistency about drug effects, it thus depended on the case as to whether the consequences of cannabis or opioids included, for example, diminished parental capacity. This was also the case for other substances. In $X$ County Council v M, F, Z (a child) by his guardian v MGPs, ${ }^{34}$ the consultant psychiatrist was "concerned that crack cocaine is not a drug that can easily be used in a controlled fashion. Use very readily turns into dependent use and this is associated with a chaotic life and a need to generate large sums of money" (para. 71). However, in $\operatorname{Re} A A, B B$ (Minors), ${ }^{35}$ the judge, in the transcript, included testimony from a psychiatrist who said that the father was "not an addict, but rather someone who chooses to take cocaine" (para 39), suggesting that use of the drug did not necessarily impact on the ability to parent. In addition to framing addiction as a condition in which 'choice' is extinguished, and users are deprived of agency, the difference between the conceptualisation of crack and powder cocaine, which was the subject of potential concern in the second case, is significant. Although the pharmacological difference the two forms of cocaine is marginal, crack attracts greater condemnation and invites harsher penalties in ways that are again heavily racialized and classed (Alexander, 2012). Determining the effects of cocaine did not, therefore, depend on the unique properties of the substance, but rather points to the mutability of drugs within discourses of knowledge production.

\section{The agency of substances}

Where drugs, or their use, were asserted to be problematic, their agentic power to produce certain effects was repeatedly asserted in the judgements as a collateral reality. Although drug effects were thus unstably constituted, when it came to determining harm, they were consistently composed as singularly and causally

\footnotetext{
332015 WL 6966268

342016 WL 07840624

352014 WL 7717465
} 
responsible for the damage caused to individuals and families. Although mediating or associated factors could be mentioned, they did not displace drugs and alcohol as the primary instigators of harm. In Bath ${ }^{36}$, the evidence provided to the court by the Guardian was as follows:

... all four children have experienced a chronically unstable, chaotic and unsafe home environment due to their mother's drug misuse, and the accompanying issues of neglect of their basic needs and poor emotional attunement (para. 7).

It was argued by $\mathrm{HHJ}$ Wildblood QC that the case demonstrated "the truly pitiful plight of a mother caught up in drug addiction" (para 1), hinting at the particularly sad and pathetic story of a mother who uses substances (the gendered implications of which will be returned to in due course). He went on:

...the greatest damage to her chances of caring for her children successfully has arisen through her long standing addiction to drugs and drink [leaving] her quite unable to care for her children at times...I found it desperately sad to see a person who has so much about her speaking of the ruination that drink and drugs have brought about. However, there is no escaping the fact that she has a chronic addiction to drugs and alcohol and has only recently begun to address that addiction which, this time, took her to the very lowest rung of the life's ladder... Her addictions have had a cluster bomb effect on her life (paras. 16-17).

The mother at the centre of the case had herself been in care during childhood, having, according to the judge "been beyond the control of her parents" (para. 3). Children in care tend to be subject to considerable disadvantage in respect of their mental health, educational provision, propensity to be involving in offending, and job opportunities (Zayed and Harker, 2015; DoE, 2016). She had her first child at the age of 17 and was, according to the judge, 'addicted' to class A drugs by the age of 20 (para. 4). HHJ Wildblood concluded that:

${ }^{36}$ [2017] EWFC B10 
This case is a very clear example of the damage that drugs can do. People like this father are all too keen to profit from the drugs market but the damage that is done through drug distribution can be seen in the decimation of this family. What to some vulnerable or impressionable people may seem cool in their teens or early twenties leads to this dreadful type of picture in later life. I hope that there is sufficient education so that this type of potential ruination is known (para.106).

In addition to identifying drug use as the primary agentic instigator of the family's demise, suggesting that the mother (or anyone else) may have begun taking drugs because it seemed 'cool' positioned abstinence as the only mature and rational drugtaking decision. It was also notable in the judgement that whereas drug addiction was isolated as causally responsible, evidence of child harm persisted even during periods when the mother was abstinent:

Following [the child's] birth in 2013 there were periods when the mother appeared to be on top of her drug addiction although there were more reports of the neglect of the children and A's school poor attendance (para. 5).

Later in the judgement, it was similarly stated that:

She says that she is now drug-free but that state of affairs has only endured for two months against seventeen years of involvement with drugs albeit with some periods of abstinence during which the same social and emotional issues continued for her (para. 27)

In London Borough of Wandsworth $v W,{ }^{37}$ drugs were similarly cited as responsible for 'ruining lives' although the mother in question had had a "very difficult childhood" (para. 10), involving a period in care, due to her own mother's mental health problems and her father's violence. At the age of 16 , she had been referred to a psychiatrist following evidence that she had been cutting herself. For Mrs Justice King, however, this was

yet another case demonstrating how drugs ruin people's lives. This mother was brought up in unbelievably adverse circumstances the result of which was the development of a significant personality disorder, a disorder which

37 [2014] EWHC 3682 (Fam) 
constantly drives her back to the drugs which have dominated her life since she was 16 (para. 60)

The causal relationship between the diagnosis of personality disorder, drug use and childhood trauma was conceived as temporally linear; adversity led to a personality disorder which caused the drug problem. It was the drugs that had 'dominated' her life (and to where she was 'driven back' to) suggesting attenuated volition and control as a direct, casual consequence. The proceedings were also described as arising "out of the mother's long history of serious substance abuse and her inability to date, notwithstanding her genuine desire to care for her children, to remain abstinent from drink and drugs" (para. 2). Similarly, in Bath, according to the judge, "the mother said, unsurprisingly, that her addictions led her into a downwards spiral of depression where she could not cope with demands of life" (para. 21). Temporality was again key: the 'real' problems always began with drugs.

In Local Authority ${ }^{38}$ the judge in the lower court had noted that family life had "deteriorated into chaos and neglect ... the causes of this are complex and intertwined", and that there had been "serious domestic violence." However, she reified drugs as the master factor in contributing to family breakdown, arguing that: "[T]his case highlights the terrible, terrible cost that drug use can have on a family" (para. 15). Similarly, in the higher court, the mother was also described as having "complex needs as a consequence of her upbringing, her life-style choices, and specifically her drug-abuse" (para. 127) [my emphasis]. In LD for the Adoption of Child $\mathrm{CH}$ (Scottish), 39 it was the mother's "ability to overcome the drug addiction which is at the heart of the problem" (para. 11), whereas in S (A Child) (Adoption Order or Special Guardianship Order), ${ }^{4041}$ the involvement of both parents in the "use of drugs...led to the now familiar situation of an ensuing chaotic life-style in squalid home circumstances resulting in inappropriate care of the child" (para. 83). The purpose here is not to suggest that those involved in the judicial process purposely make such causal links, but they do reflect the inclination to locate the cause of a variety of 'problems', from crime to family breakdown, in individual drugusing subjects (Stevens, 2011; Moore and Fraser, 2015; Seear, 2017; valentine \&

\footnotetext{
38 [2014] EWHC 2042 (Fam)

392011 WL 4966507

40 [2007] EWCA Civ 54

41 [2013] EWHC 4501 (Fam)
} 
Fraser, 2008).

\section{Gendered judgements}

As noted above, gender has been identified as intrinsic to the ways in which addiction and substance use are understood. Using Karen Barad's (2003) notion of posthumanist performativity, Dwyer and Fraser (2017) have drawn attention to the ways in which research itself, and particularly diagnostic tools, can help to materialise gender by, for example, constituting men and women's drug use differently. According to Moore and Measham (2013: 83) “'Woman as victim' remains the dominant model through which women's relationships with substances and with other people are understood; a model often internalized by women themselves." Paternalistic accounts of victimhood, pathology and vulnerability, which have historically infused both academic and public discussions about female substance users (Ettorre et al., 2008: 3) have thus dovetailed with discourses of responsibility and blame. Judicial constructions of the life narratives of mothers tended to draw on either bad choices, and deviant behaviours, or the 'tragic' histories of women caught up in cycles of deprivation and abuse. Personal culpability, and a dereliction of duty, nevertheless held particular explanatory force during consideration of the difficulties experienced. The permission to mother was generally contingent on abstinence from drugs.

In Bath, the father had also been identified as a user of crack cocaine and possibly heroin (para. 42), but it was the mother's 'plight' that was 'truly pitiful', and, seemingly, particularly ill-befitting of a mother and woman. The judge found the father to be a "very self-centred, controlling and over assertive man" but did not delve into the father's background circumstances, or consider any explanation for his ascribed characteristics (para. 47). It was also determined that "the greatest damage to [the mother's] chances of caring for her children successfully has arisen through her long-standing addiction to drugs and drink" (para. 16). There was no suggestion that the lack of support from any of the children's fathers may also have been integral to the decision to deny care. Indeed, the judge himself acknowledged that the mother "did not get any consistent help from any of the children's fathers" (para. 
15), and noted that the father in the case "dipped in and out of the mother's life when it suited him" and that "when the mother was struggling with drug addiction and the care of four children there is no evidence to suggest that the father supported her" (para. 20). The mother's physical appearance, but not the father's, was also deemed pertinent; she was described as being in her "late 30's [sic]" and as "an attractive, polite and intelligent woman who readily acknowledged that she had gone off the rails...(para. 13).

Research has indicated that if a mother's needs are routinely relegated to below those of her child, her incentive to cooperate with services is lessened (Waldby, 1986: 83; Fraser and valentine, 2008). At the same time, evidence of resistance to interventions and treatment plans could result in refusing residence or contact to mothers, meaning they were caught in a double bind. In $M v$ Warwickshire County Council ( $M$ and another intervening), ${ }^{42}$ for example, the mother was considered to be "unable to properly look after herself" while "abusing alcohol and crack cocaine" (para. 10). Yet the judge also regretted that she had "failed to access help in overcoming those problems even for the sake of the children" (para. 10) [my emphasis], reinforcing the construction of 'good' motherhood as an exercise in selfsacrifice, and characterising the mother as doubly deviant for failing to access help while being a parent. In Tameside Metropolitan Borough Council v KH, AC, ISH (a child by her children's guardian, Gill Pearson), ${ }^{43}$ the mother had conceded that she lied to her GP and social worker about her drug use because they "would have talked her out of it...

She had said she "made an active choice to use it ". She had chosen to do so because she said she was still being told she was not good enough to care for [the child]. She had known she had to stay abstinent (para. 73).

The decision to highlight this incident in the judgement evinces the ways in which autonomous decisions to use drugs attracted condemnation from health and social service providers, and the courts. In a study of methadone maintenance treatment (MMT), Fraser and valentine (2008), found that MMT builds a gendered notion of

\footnotetext{
42 [2007] EWCA Civ 1084

432016 WL 07048590
} 
passivity as part of an attempt to 'structure' the lives of men and women. For female clients in particular, if they challenged expectations they were understood to be transgressing "traditional ideals of femininity...quiet, retiring and subject to, rather than sovereign of, expert discourse" (Fraser \& Valentine, 2008: 153). In Tameside, ${ }^{44}$ it was recommended by a doctor that, among other requirements, the mother needed to stop 'self-medicating' with drugs and alcohol, and undertake cognitive behavioural therapy (para. 9). There was particular concern about the mother's dishonesty in respect of her alcohol and drugs intake, and her failure to report a relapse to the local authority (paras. 9, 35, 54). According to evidence from the doctor, the mother "makes bad choices and is anti-authority and likes doing her own thing" (para. 55), suggesting that the "underlying issues may be her personal preferences" (para. 56).

Similarly, in $S$ (A Child) ${ }^{45}$ the expert doctor found the mother to be "highly defensive in responding to psychological questionnaires", and he regarded this as "likely to be part of her rather emotionally repressed state, being a legacy of her drug use" (para. 93). He went on to argue that the "main psychological issues for (the mother) have been her drug use, her previous violent intimate relationship, her lifestyle and her emotional stabilities" (para. 95). Drugs were again causally responsible for the mother's emotional deficits, meriting a privileged position in the list of problems that she had been experiencing. Drug use could thus be both evidence of a mother's psychological inadequacies, and also comprise the cause of personality deficits such as 'emotional repression'.

The representation of the relationship between drugs and domestic violence in a number of cases was troubling due to the implications for attributing responsibility. Research has found that men may use intoxication in order to excuse their own violent behaviour (Abrahamson, 2006), and that alcohol may be used to explain rape or mitigate responsibility (Bernhardsson and Bogren, 2012; Finch and Munro, 2007). In the judgements, women who had experienced domestic violence were in some cases held responsible for entering into the relationships in the first place, or failing

\footnotetext{
${ }^{44} 2016$ WL 07048590

45 [2007] EWCA Civ 54
} 
to seek appropriate support. In Tameside ${ }^{46}$, the judge stated that:

It is clear that each intimate relationship which the mother has had has involved either domestic violence, alcohol or substance misuse and the evidence shows that she engages in risky relationships which progress very quickly with no thought for the consequences (para. 86).

The purported risks to children thus authorised gendered judgements about women's responsibility for relationship violence and abuse. In $M v$ Warwickshire County Council ( $M$ and another intervening) ${ }^{47}$ the mother was described as 'immature' (para. 10) and "prone to abusive relationships." In some cases, the use of drugs was also judged to have 'caused' domestic violence incidents. In West Sussex County Council $v \mathrm{~J} \&$ Anor, the judge, referring to incidents of domestic violence, said that the "very unstable situation was exacerbated by the mother and possibly the father taking drugs" (para. 13). In $J \vee G,{ }^{48}$ the judge in the lower court "found and it was not disputed before us that the central reason for the problems between the parties was that $\mathrm{J}$ habitually used alcohol and drugs to excess which resulted in volatile and unpredictable behaviour on his part" (para. 5). He also argued that living with the father "inevitably brings with it a real and sustained fear of physical harm as a direct result of him losing self-control through drink and drugs" (para 6).

It was expected that partners and family members, but particularly women, acted as 'gatekeepers' in preventing their loved ones from taking, or wanting to take, substances, supporting the claim that woman's idealized role within the traditional family can centre on female (but not male) drug users' 'inability' to keep their families together (Hannah-Moffat, 2007: 230). Expectations about the 'natural' role of mothers feeds into well-established scholarship on the social construction of motherhood, and observations about the ways in which the law shapes normative ideals about women and mothers (a woman must be a mother, selflessly available to her children, and so on) (Smart, 1991; Diduck, 1993). Child protection law, in particular, can create an opposition between the rights of children and mothers, so that women may be held individually responsible for failing to protect their children from socio-economic risks such as poverty (Kline, 1993).

\footnotetext{
462016 WL 07048590

47 [2007] EWCA Civ 1084

48 [2015] NICA 23
} 
In Re: G (Care Order), 49 "the grandmother...colluded with the mother in the mother's drug taking and...she has continued to indulge her daughter's self abuse" (para. 52). In Re P (A Child: Assessment of Kinship Carers) ${ }^{50}$, there was implicit criticism of a prospective kinship mother's failure to report her partner's cannabis use, who was also a potential carer. According to the judge, the mother "knew that he was being economical with the truth. She could have contradicted him. She didn't. When asked why, she said that 'it was [the partner's] issue'. Her written evidence is completely silent about [the partner's] cannabis use' (para. 46). In X County Council v $M 1$ \& M2, $F 1 \& F 2, A, B$ (by her Children's Guardian) ${ }^{51}$, there was also an expectation that prescribed substances were monitored. Mr Justice Cobb expressed his disapproval of a mother's (M1) comments about her partner's (M2) prescription drug use. He said:

I cannot pass up discussion of this topic without remarking how struck I was by M2's evidence relevant to this point; when cross-examined... she told me that "I would not know what dosage (of prescribed drugs) she takes" and added in my view, indignantly, "I am not her nurse ... I have not been watching her medication." Later...she added: "I hate the fact that there is an imbalance in the relationship, because of her illness. I do not want to be her jailer." I have to say that I found those answers, and the tone of them, extremely surprising (para. 86).

Although in Local Authority it was the father who had been identified as failing to support his wife by drinking in front of her, prioritising "his own wish for alcohol over support for his wife in her recovery," 52 it was largely women, whether mothers, aunts or grandmothers, who were expected to assume the gatekeeping role. The judge in Local Authority thus also considered whether the mother's potential failure to protect her children from the alcohol abuse of the father affected her ability to meet their needs under Section 1(3)(f) of the Children Act (para. 57). He said:

...there are some areas of these children's care needs where the mother's abilities are as yet untested. These include, for example, her ability to protect

\footnotetext{
49 [2003] EWHC 1711 (Fam)

502014 WL 2931274

51 [2014] EWHC 818 (Fam)

52 [2014] EWHC 2042 (Fam), para. 154.
} 
the children from physical and emotional harm if, following reunification, the father were again to be violent towards her or to abuse alcohol [my emphasis].

Such observations placed women as the primary protectors and of the family, and principle guardians of children's welfare.

\section{Abstinence and honesty: performing capable parenthood}

Although drug use is not supposed to act as a bar to assignations of 'good enough' parenting, in reality addiction was mainly formulated as antithetical to capable parenting in the cases surveyed, and abstinence was privileged as key to preventing harm to children. In Local Authority ${ }^{53}$, for example, in which the mother was identified as having problems with cocaine and alcohol, there was a requirement for "proven abstinence and sobriety before she can be an effective parent" (para. 267). However, given that 'dependence' on heroin substitutes, and the occasional use of cocaine or cannabis, was not deemed to pose a threat to retaining the care of children in most cases, the production of realities about parenting and drug use or addiction was inconsistent. Moreover, evidence of abstinence was, paradoxically, not necessarily concerned with being drug-free, but about demonstrating characteristics of responsibility and self-sacrifice that were considered necessary, as a collateral reality, for capable parenting. As such, although the drug-free/drug addict dualism proved to be a powerful source of governance in the cases described, admitting that one had a drug 'problem' or had experienced a relapse was also instrumental. Such exigencies reflect the requirements of advanced liberal citizenship: one must be responsible, self-governing and autonomous, whilst acknowledging and correcting one's failures (Foucault, 1978: 58). Drug testing was used in order to determine a parent's honesty, particularly in cases where care arrangements were contingent on parental abstinence, although there has been controversy over the use of hair-strand testing for drugs and alcohol in family courts, ${ }^{54} 55$ and judges have cautioned against "relying on the science alone without regard to the wider picture." 56 In Canada, an

\footnotetext{
53 [2014] EWHC 2042 (Fam)

${ }^{54}$ Bristol City Council v A and A, and SB and CB, and Concateno and Trimega (interveners) [2012] EWHC 2548

${ }^{55}$ See also Barrow A. and Round Z. (2014) 'The pitfalls of hair testing', Family Law Week, accessible at: http://www.familylaw.co.uk/news and comment/the-pitfalls-of-hair-testing\#.WYA3PemQzIV 56 Per Mr Justice Cobb in Local Authority 1 \& Others v AF (Mother) \& Others [2014] EWHC 2042 (Fam), para. 145.
} 
independent review into hair testing in one laboratory found that 'flawed' methods "had serious implications for the fairness of child protection and criminal cases" (Lang, 2015: 4). In Local Authority, ${ }^{57}$ the judge in the lower court had been concerned about the parents' "ability to abstain from drug use, and maintain abstinence - a concern compounded by... the mother's lies about her drug use/relapsing" (para. 143). Similarly, a failure to acknowledge that one had a 'problem' was looked on unfavourably by the court, and could be used as evidence of a parent's poor attitude. In $\operatorname{Re} A$ (Children) $^{58}$, the judge stated that:

Without hesitation I find that it is entirely appropriate to describe Father's substance misuse as long-standing and his failure to acknowledge this in his evidence demonstrated the sort of unhelpful and truculent attitude which pervaded a significant part of his oral evidence (para. 28).

The discourses of medicine and psychology have tended to frame drug use as an individualised problem that can only be treated through the intervention of expert doctors and therapists (Moore and Measham, 2013; Flacks, 2017). It is thus perhaps not surprising that treatment and psychological technologies such as Cognitive Behavioural Therapy were privileged as the main ways in which parents could 'recover' and become good enough parents. Recall also that for HHJ Wildblood QC in Bath, trying drugs indicated some vulnerability and impressionability. At the same time, drug-taking was considered to be a consequence of immaturity and irresponsibility, reflecting the ambivalent and paradoxical construction of drug-taking and addiction as behaviours that are associated with both victimhood and blame. In Aberdeen City Council v R, Sheriff Court of Grampian, Highland and Islands at Aberdeen ${ }^{59}$, it was concluded that "the respondent led an irresponsible life. She abused and became addicted to controlled drugs, including heroin" (para. 52). In $L$ (A Child) ${ }^{60}$ the lower court judge said:

no assumptions can be made at present about whether $F$ will succeed in remaining free from drugs and mature into a responsible person who can

\footnotetext{
57 [2014] EWHC 2042 (Fam)

582016 WL 05864928

592004 S.L.T. (Sh Ct) 53

60 [2007] EWCA Civ 196
} 
shoulder all the burdens of his complicated life and restrain himself from inappropriate behaviour (para. 16).

Drug-taking was thus a marker of immaturity, suggesting a failure of responsibility and self-control, and parents were praised for demonstrating a willingness to align themselves with the court's interest in producing willingly-governed, docile subjectivities (Foucault, 1986). They were thus "brave" for acknowledging they had a drug problem and were therefore incapable of parenting. ${ }^{6162}$ This coupling of 'addiction' with irresponsibility identified parents as deficient in the rationality and self-control that were necessary for exercising moral agency and reproductive citizenship (Fraser Moore and Keane, 2014: 875).

\section{Conclusion}

The aim of this paper has been to examine the ways in which drugs and their harms are constituted in reported cases in the family court, and how these 'truths' intersect with those concerning parenting and, particularly, motherhood. It was found that 'drugs' and 'problem use' (and its various iterations, such as 'addiction' and 'misuse') were unstable terms, although reductive judicial truth-making attempted to establish and stabilise them as pre-existing phenomena that could be located in both individual pathology and irresponsible decision-making. Attempts to quantify the detrimental, or otherwise, effects of the substances themselves were similarly variable and contingent. Nevertheless, substance (mis)use - however constituted tended to be identified as causally responsible for family problems, or child harm, even where the difficulties appeared to emanate from a more complex array of factors such as a lack of social support (notably from fathers), financial problems, mental health issues (which interact with substance use in complex ways), and domestic violence. The relationship between substance use and motherhood was constructed as especially problematic, suggesting that mothers may be held accountable for both the transgression of gender norms as a result of drug use, and for failing to conform to the ideals of the maternal role.

\footnotetext{
${ }^{61}$ Bath, para. 29, HHJ Corbett, London Borough of Hillingdon v A, B, para. 54

62 R (Children) [2005] EWCA Civ 516
} 
The ways in which parenting, drugs and addiction are made in court has important effects, not least for the children and parents involved in proceedings, and there should be greater attendance to the ways in which accounts of drug harms, behaviours and effects are sustained and stabilised in family courts. The identification of substance use as the prime causal factor in 'failed' families can mean that evidence of structural and social disadvantages become framed as matters of personal responsibility through blaming parents, usually mothers, for failing to abstain. Locating responsibility for child harm solely within the decisionmaking of parents, valorising the family as a socially disembodied locus of child wellbeing (and therefore future productivity), is in keeping with neoliberal rationalities in which individualist modes of thinking prioritise abstinence from drugs as necessary for responsibilised citizenship.

Moreover, where drugs and alcohol operate as touchstones for 'bad parenting', decisions to prevent contact or deny residence can be justified and simplified despite uncertainty and ambiguity about the risks posed. Harm reduction specialists have expressed concern about the lack of space that is "encouraging of open talk and reflection about what amounts to good parenting in the face of problem drug use" and that this "heightens the social and other harms of parental disclosure, in turn reinforcing strategies of damage limitation which emphasise secrecy, ambiguity and denial" (Rhodes et al., 2010: 1496). The appearance of neutral attributions of risk and harm, framed according to children's 'welfare' and supported by 'scientific' evidence supplied to the court, can mask normalising projects. Moreover, the naturalisation of mothers' role as guardians of children's welfare has troubling implications for the ways in which care cases are adjudicated, and the designation of substance use as a causal factor in domestic violence raises important questions about the attribution of responsibility for abusive behaviour. Given the variability of concepts such as 'drugs' and 'addiction', and the contingent ways in which people are affected, it is important to consider how reductive judgements about parental substance use might limit understandings of children's welfare and reinscribe gendered expectations about care-giving. 


\section{References}

Abrahamson, M. (2006) 'Young Women's and Men's Different Worlds of Alcohol, Fear and Violence in Focus Group Discussions with 18-year-olds in Stockholm,' Contemporary Drug Problems 33: 3-27.

Adamson J, Templeton L. (2012) Silent voices: supporting children and young people affected by parental alcohol misuse. London: Children's Commissioner's Office.

Alexander M. (2012) The New Jim Crow: Mass Incarceration in the Age of Colourblindness, New York: The New Press

Bancroft A. and Wilson S. (2007) 'The 'Risk Gradient' in policy on children of drug and alcohol users: Framing young people as risky,' Health, Risk and Society, 9(3),. 311-322

Barad, K. (2003) 'Posthumanist Performativity: Toward and Understanding of How. Matter Comes to Matter", Signs, 28(3)

Barnard and McKeganey (2004) 'The impact of parental problem drug use on children: what is the problem and what can be done to help?', Addiction, 99(5):552-9. 
Benoit C, Stengel C, Marcellus L, Hallgrimsdottir H, Anderson J, MacKinnon K, et al. (2014) 'Providers' constructions of pregnant and early parenting women who use substances', Social Health IIIn.;36(2):252-63

Bernhardsson, J., and A. Bogren (2012) "Drink Sluts, Brats and Immigrants as Other: An Analysis of Swedish Media Discourse on Gender, Alcohol and Rape," Feminist Media Studies 12 (1): 1-16.

Berns S., (2000) 'Folktales of legality: family law in the procedural republic' (2000) 11 (1) Law and Critique 1, 4

Boyd, S. (1999). Mothers and illicit drugs: Transcending the myths. Toronto: University of Toronto Press.

- (2004). From witches to crack moms: Women, drug law, and policy. Durham, N.C.: Carolina Academic Press

Boyd S. and Carter C. (2011) 'Using Children: Marijuana Grow-ops, Media, and Policy', Critical Studies in Media Communication, pp. 1-20

Cain R. (2011) 'The Court of Motherhood: Affect, Alienation and Redefinitions of Responsible Parenting,' in Bridgeman J., Keating H., and Lind C. (eds.) Regulating Family Responsibilities, Ashgate

Campbell N. and Ettorre (2011) Gendering Addiction: The Politics of Drug Treatment in a Neurochemical World, London: Palgrave

Children and Young People Now (2009) 'Should the children of drug addicts be taken into care?' Children and Young People Now, August 27, at: http:// www.cypnow.co.uk/Archive/929088/children-drug-addicts-taken-care/

Comiskey C, Milnes J. \& Daly M. (2017) 'Parents who use drugs: the well-being of parent and child dyads among people receiving harm reduction interventions for opiate use', Journal of Substance Use Vol. 22(2).

Couvrette A., Brochu S. Plourde C. (2016) 'The "Deviant Good Mother": Motherhood Experiences of Substance-Using and Lawbreaking Women', Journal of Drug Issues, 46(4) $292-307$

Department of Education (DoE) (2016) Children looked after in England (including adoption) year ending 31 March 2016, London: Department for Education 
Derrida, J. (1993). The rhetoric of drugs. An interview. differences: A Journal of Feminist Cultural Studies, 5(1), 1-25.

Diduck, A. (1993) 'Legislating Ideologies of Motherhood' 2 Social \& Legal Studies 461

Duff C. (2012) 'Accounting for context: Exploring the role of objects and spaces in the consumption of alcohol and other drugs', Social and Cultural Geography, 13(2) 145-159.

Ettorre, E. (2007). Revisioning women and drug use: Gender, power and the body. Basingstoke: Palgrave Macmillan.

Ettore E, Mullins C, Sommers I, Baskin D, Katsulis Y, Blankenship K, Saum C, Gray A, Kelley M, Malloch M. (2008) Neither villain nor victim: Empowerment and agency among women substance abusers. Brunswick, New Jersey: Rutgers University Press New.

Finch, E., and V. Munro (2007) 'The Demon Drink and the Demonized Women: Socio-sexual stereo-types and Responsibility Attribution in Rape Trials Involving Intoxicants', Social \& Legal Studies 16(4): 591-614.

Foucault M (1986) The history of sexuality, Vol. 3, The care of the self. Trans. R. Hurley. Harmondsworth, UK: Penguin

Fraser, S. \& valentine, K. (2008). Substance and substitution: Methadone subjects in liberal societies. New York: Palgrave Macmillan

Fraser, S., Moore, D. and Keane, H. (2014) Habits: Remaking Addiction. Basingstoke: Palgrave Macmillan.

Gillies V. (2005) 'Raising the 'Meritocracy' Parenting and the Individualization of Social Class', Sociology, 39(5)

- (2007) Marginalised Mothers: Exploring Working Class Experiences of Parenting, Abingdon, Routledge.

- (2014) 'Troubling families: parenting and the politics of early intervention', in: Wagg, S. and Pilcher, J. (ed.) Thatcher's Grandchildren Politics and Childhood in the Twenty-First Century, London: Palgrave Macmillan 
Hannah-Moffat, K. (2007). Gendering dynamic risk: Assessing and managing the material identities of women prisoners (Chapter 11). In K. Hannah Moffat \& P. O'Malley (Eds.) Gendered risks. London: Routledge.

Harding M. and Newnham A., (2015) How do county courts share the care of children between parents? London: Nuffield Foundation

Hart, A.C. and Moore, D. (2014) 'Alcohol and alcohol effects: Constituting causality in alcohol epidemiology', Contemporary Drug Problems, 41, (3): 393-416

Harwin J. et al. (2016) After FDAC: outcomes 5 years later, Lancaster University, Bailrigg, Lancaster

Holland S., Forrester D. Williams A., Copello A. (2013) 'Parenting and Substance Misuse: Understanding Accounts and Realities in Child Protection Contexts', The British Journal of Social Work, 44(6): 1491-1507

Holt, A. (2008) 'Room for resistance? Parenting orders, disciplinary power and the production of 'the bad parent', in ASBO Nation: The Criminalisation of Nuisance, edited by P. Squires. Bristol: Policy Press, 203-22

Hunt, J. and Macleod, A. (2008) Outcomes of applications to court for contact orders after parental separation or divorce. London: Ministry of Justice

Keane, H. (2002). What's wrong with addiction? Carlton South: Melbourne University Press.

Kline, M. (1993) 'Complicating the Ideology of Motherhood: Child Welfare Law and First Nation Women'. 18 Queen's Law Journal 306-342.

Kroll B. (2004) 'Living with an elephant: growing up with parental substance misuse', Child and Family Social Work 9: 129-140

Lang S. (2015) Report of the Independent Reviewer of the Motherisk Hair Analysis Review, available at: http://www.m-hair.ca/

Law, John (2004) After Method: Mess in Social Science Research. International library of sociology, London: Routledge

Lister, R. (2003) 'Investing in the citizen-workers of the future: Transformations in citizenship and the state under New Labour', Social Policy and Administration, 37(5), 427-43 
Mol, A. and Law, J. (2002). Complexities: An introduction, in Complexities: Social Studies of Knowledge Practices, edited by J. Law \& A. Mol. Durham: Duke University Press, 1-22.

Mol, A. (2002) The Body Multiple: Ontology in medical practice, Durham: Duke University Press.

Moore K. and Measham F. (2013) 'Exploring Emerging Perspectives on Gender and Drug Use' in Mistral W (ed.) Emerging Perspectives on Substance Misuse, John Wiley \& Sons, Ltd.

National Health Service (2012) Parents with drug problems: how treatment helps families, London: National Treatment Agency for Substance Misuse

Peacey, V. and Hunt, J. (2008) Problematic contact after separation and divorce? A national survey of parents, One Parent Families, Gingerbread.

Race, K. (2011) 'Drug effects, performativity and the law', International Journal of Drug Policy, 22(6), 410-412

Rhodes, T; Bernays, S; Houmoller, K; (2010) Parents who use drugs: Accounting for damage and its limitation. Social science \& medicine, 71 (8). pp. 1489-97

Roberts, D (1991) 'Punishing drug addicts who have babies: women of colour, equality and the right of privacy, Harvard Law Review, 104(7)

Seear, K. (2015) "Making addiction, making gender: A feminist performativity analysis of Kakavas v Crown Melbourne Limited" The Australian Feminist Law Journal 41 (1): 65-85

Seear K. and Fraser S. (2014) 'Beyond criminal law: The multiple constitution of addiction in Australian legislation', Addiction Research \& Theory, 22(5)

Smart, C. (1991) 'The Legal and Moral Ordering of Child Custody' 18(4) Journal of Law and Society 485-500

Valentine, K. and Fraser, S. (2008), "Trauma, Damage, and Pleasure: Rethinking Problematic Drug Use," International Journal of Drug Policy, 19: 410-416 van Krieken R., (2005) 'The 'Best Interests of the Child' and Parental Separation: on the 'Civilizing of Parents', Modern Law Review 68(1): $25 \square 48$ 
Waldby, C. (1986). Mothering and addiction: Women with children in methadone programs (monograph series no. 4). Canberra: Australian Government Publishing Service

Zayed Y. and Harker R. (2015) Children in Care in England: Statistics, House of Commons Briefing Paper 04470, 